\title{
HUBUNGAN PENGETAHUAN SISWI DENGAN MINAT DALAM PEMILIHAN PEMBALUT KAIN
}

\author{
Knowledge Of Students With Interest In The Selection Of Clothing Fabric
}

\author{
Ayu Puspita I* \\ Septian Mugi Rahayu ${ }^{2}$ \\ Amelia Excoelsa ${ }^{3}$
}

13Prodi Sarjana IImu

Keperawatan, STIKES Eka

Harap, Palangka Raya, Indonesia

2Prodi Profesi Ners, STIKES

Eka Harap, Palangka Raya,

Kalimantan Tengah, Indonesia

*email:

ayubrilianydedy@gmail.com

\begin{abstract}
Abstrak
Pembalut wanita saat menstruasi adalah kebutuhan utama. Menurut penelitian, pembalut wanita sekali pakai yang sekarang digunakan bersifat karsinogenik dam mengandung zat berbahaya yang berpotensi menyebabkan penyakit berbahaya bagi organ reproduksi. Tujuan umum penelitian ini adalah untuk mengetahui hubungan pengetahuan siswi dengan minat dalam pemilihan pembalut kain. Desain penelitian ini menggunakan desain literatur review. Artikel dikumpulkan dengan menggunakan mesin pencari seperti EBSCO, Sciencedirect, Proquest dan Google Scholar. Kriteria artikel yang digunakan adalah yang diterbitkan tahun 2019 dan 2020. Berdasarkan artikel yang dikumpulkan didapatkan hasil bahwa terdapat hubungan pengetahuan dengan minat. Menurut peneliti hal ini terjadi dikarenakan ketiga penelitian ini memiliki karakteristik subjek yang sama, yaitu responden penelitian merupakan perempuan yang sudah mengalami menstruasi dan kesamaan penelitian dalam pemilihan pembalut yang tepat dan aman untuk kesehatan reproduksi perempuan. Seorang wanita diharapkan dapat memilih pembalut yang tepat. Kesalahan memilih pembalut bisa berakibat iritasi kulit, alergi, hingga penyakit kulit dan infeksi. Pemilihan pembalut juga disesuaikan degan aktivitas yang akan dilakukan seorang wanita.
\end{abstract}

Kata Kunci:

Pengetahuan

Minat

Pembalut

\section{Keywords:} Knowledge Interest

Bandages

\begin{abstract}
Sanitary napkins during menstruation are the main requirement. According to research, disposable sanitary napkins currently used are carcinogenic and contain harmful substances that have the potential to cause dangerous diseases for the reproductive organs. The general objective of this study was to determine the relationship between student knowledge and interest in the selection of cloth sanitary napkins. The design of this study used a literature review design. Articles are collected using search engines such as EBSCO, Sciencedirect, Proquest and Google Scholar. The criteria for the articles used were those published in 2019 and 2020. Based on the articles collected, it was found that there was a relationship between knowledge and interest. According to the researchers this happened because these three studies had the same subject characteristics, namely the research respondents were women who had experienced menstruation and the similarity of research in choosing the right and safe sanitary napkins for women's reproductive health. A woman is expected to be able to choose the right sanitary napkin. Mistakes in choosing pads can result in skin irritation, allergies, to skin diseases and infections. The choice of sanitary napkins is also adjusted to the activities a woman will do.
\end{abstract}

(C) year The Authors. Published by Institute for Research and Community Services Universitas Muhammadiyah Palangkaraya. This is Open Access article under the CC-BY-SA License (http://creativecommons.org/licenses/by-sa/4.0/). DOI: https://doi.org//0.33084/jsm.vxix.xxx.

\section{PENDAHULUAN}

Pembalut wanita merupakan produk sekali pakai yang biasa digunakan wanita setiap bulannya (Wati et al., 2019). Pembalut wanita saat menstruasi adalah kebutuhan utama. Menurut penelitian, pembalut wanita sekali pakai yang sekarang digunakan bersifat karsinogenik dam mengandung zat berbahaya yang berpotensi menyebabkan penyakit berbahaya bagi organ reproduksi (Habibie et al., 2019). Pembalut Herbal menggunakan pewangi yang bisa membunuh bakteri baik dan dan memicu berkembangnya bakteri jahat sehingga bisa memicu infeksi bakteri (Susanti \& Wijaya, 2018). 
Data Global Cancer Observatory 2018 dari Word Health Organization (WHO) menunjukkan kasus kanker serviks ( leher rahim ) di Indonesia sebanyak 32.469 kasus atau 9,3\% dari total kasus. Merujuk data yang dipaparkan Kemenkes per 31 Januari 2019, terdapat angka kanker serviks sebesar 23,4 per 100.000 penduduk dengan rata-rata kematian 13,9 per 100.000 penduduk. (Kementrian Kesehatan RI, 20I8). Deteksi dini terhadap kanker, telah dilaksanakan sejak 2015 di Kota Palangka Raya dan pada prioritas paling atas adalah deteksi kanker leher rahim. Pada tahun 2018 terdapat I\% ( 6 kasus ) IVA positif dan 2\% ( 8 kasus ) penemuan tumor/benjolan, dari 444 total sampel ( pada perempuan usia 30-50 tahun. Sedangkan pada tahun 2017 tampak penurunan IVA positif sebanyak 8 kasus $0,90 \%$ dan penemuan tumor/benjolan sebanyak I kasus 0,10\% dari total pemeriksaan sebanyak 893 orang perempun usia 30-50 tahun (Dinas Kesehatan Kota Palangka Raya, 2018). Berdasarkan data saat survey pendahuluan pada tanggal 24 Februari 2020 dengan wawancara pada siswi di SMP Santa Maria Palangka Raya yang berjumah 5 orang siswi yang sudah mengalami menstruasi, data yang diperoleh dari hasil wawancara tersebut adalah 3 dari antara 5 (60\%) siswi tersebut kurang mengetahui tentang jenis bahan baku pembalut,bahan kimia yang terdapat didalam pembalut dan bahaya yang disebakan oleh pembalut berbahan kimia terhadap kesehatan reproduksi.

Saat ini pembalut yang beredar di masyarakat dan banyak diminati adalah pembalut sekali pakai. Menurut penelitian terdapat sebanyak 107 bakteri per milimeter persegi ditemukan di atas pembalut wanita biasa, kondisi inilah yang membuat pembalut biasa menjadi sumber sarang pertumbuhan bakteri merugikan, meski pembalut biasa hanya dipakai selama 2 jam saja (Susanti \& Wijaya, 2018). Data penelitian tentang kesehatan reproduksi menyatakan bahwa $75 \%$ wanita di dunia pernah mengalami fluor albus (keputihan) paling tidak sekali dalam hidup dan $45 \%$ diantaranya mengalami fluor albus 2 kali atau lebih. Penyebab tersering fluor albus (keputihan) patologis adalah infeksi. Pembalut Herbal menggunakan pewangi yang bisa mem bunuh bakteri baik dan dan memicu berkembangnya bakteri jahat sehingga bisa memicu infeksi bakteri. Pemakaian Pantyliner merupakan salah satu faktor predisposisi timbulnya keputihan (Susanti \& Wijaya, 2018). Seorang wanita diharapkan dapat memilih pembalut yang tepat. Kesalahan memilih pembalut bisa berakibat iritasi kulit, alergi, hingga penyakit kulit dan infeksi. Pembalut juga tidak mengandung pewangi dan materialnya tidak terlalu padat atau ringan. Semua kriteria ini agar sirkulasi udara di vagina tetap ter jaga, senantiasa kering sebab keadaan lembab membuat bakteri lebih mudah berkembang biak dan menyebabkan iritasi. Pemilihan pembalut dengan kriteria di atas juga disesuaikan degan aktivitas yang akan dilakukan seorang wanita. Misalnya pembalut yang lebih lebar saat tidur dan pembalut tipis saat beraktivitas. Di era modern ini wanita membu tuhkan lebih menyukai pembalut yang praktis sekali pakai. Pembalut wanita sekali pakai mengandung bahan berbahaya sehingga perempuan harus sering berganti. Pembalutm sekali pakai juga memperbanyak sampah plastik sulit didaur ulang. Muncul terobosan untuk kembali menggunakan pembalut wanita berbahan kain yang biasa dicuci ulang sehingga lebih hemat dan mengurangi pembuangan sampah pembalut yang mengandung bahan sulit diurai oleh alam. Penggunaan kembali pembalut dengan bahan kain haruslah memenuhi aspek praktis sehingga cocok untuk dipergunakan oleh wanita masa kini yang sibuk dengan berbagai aktivitas (Ardiyati \& Pramitasari, 2019).

Berdasarkan masalah diatas pengetahuan siswi mengenai pembalut kain sangat diperlukan agar masalah kesehatan genetalia terutama kanker serviks dapat dicegah sejak memasuki masa remaja. Disini perawat mempunyai peran penting dalam usaha promotif yang meliputi promosi tentang kesehatan seperti memberikan informasi tentang dampak postif 
dari pengunaan pembalut kain terhadap kesehatan reproduksi wanita. Untuk itu peneliti tertarik untuk meneliti hubungan pengetahuan siswi dengan minat dalam pemilihan pembalut kain.

\section{METODOLOGI}

\section{Desain Penelitian}

Desain penelitian ini menggunakan desain literatur review. Artikel dikumpulkan dengan menggunakan mesin pencari seperti EBSCO, Sciencedirect, Proquest dan Google Scholar. Kriteria artikel yang digunakan adalah yang diterbitkan tahun 2019 dan 2020

\section{Teknik Pengumpulan Data}

Sumber data pada penelitian ini menggunakan data sekunder, dimana data yang didapatkan merupakan dari hasil penelitian terdahulu, kemudian peneliti mencari data dokumenter yang sudah dikumpulkan oleh orang lain dan didokumentasikan atau telah dipublikasikan.

Tahap selanjutnya peneliti mengumpulkan data yang sudah tersedia dalam dokumen. Kemudian peneliti membuat data dari berbagai sumber sesetara mungkin agar menjadi satu bentuk yang sama, dengan kata lain peneliti menormalisasikan data jika diperlukan dan memungkinkan. Dan tahap terakhir adalah menganalisis data sekunder tersebut.

\section{Teknik Analisis Data}

Analisis dalam penelitian ini berupa analisis sekunder yang meliputi:

I. Reduksi data

2. Penyajian data

3. Penarikan kesimpulan

\section{HASIL DAN PEMBAHASAN}

HASIL

Tabel I. Artikel terkait hubungan pengetahuan siswi dengan minat Dalam pemilihan pembalut kain

\begin{tabular}{llll}
\hline Nama & Tindakan & Hasil Penelitian & Metode \\
\hline
\end{tabular}

\begin{tabular}{|c|c|c|c|}
\hline Peneliti & $\begin{array}{l}\text { Yang } \\
\text { Diberikan }\end{array}$ & & Digunakan \\
\hline $\begin{array}{l}\text { Diiniyati } \\
\& \\
\text { Kusmary } \\
\text { ati } \\
(2020)\end{array}$ & $\begin{array}{l}\text { Pembalut } \\
\text { kain ini di } \\
\text { uji coba } \\
\text { terbatas } \\
\text { dan di uji } \\
\text { coba } \\
\text { dilapangan } \\
\text { pada } \\
\text { perempua } \\
\text { n di RT } \\
09 \\
\text { Buluran } \\
\text { Kenali } \\
\text { Kota } \\
\text { Jambi. } \\
\text { Subjek } \\
\text { pada } \\
\text { penelitian } \\
\text { ini } \\
\text { berjumlah } \\
33 \text { orang }\end{array}$ & $\begin{array}{lr}\text { Uji coba } & \text { di } \\
\text { daptkan hasil rata- } & \\
\text { rata dalam } & \\
\text { menjawab } & \\
\text { instrument } & \\
\text { mencapai } & 90 \% \\
\text { sehingga } & \\
\text { menghasilkan } & \\
\text { pembalut kain } \\
\text { yang ramah } \\
\text { lingkungan. }\end{array}$ & $\begin{array}{l}\text { Penelitian ini } \\
\text { merupakan } \\
\text { penelitian } \\
\text { pengembangan } \\
\text { (research and } \\
\text { development)de } \\
\text { ngan } \\
\text { pendekatan } \\
\text { kuantitaif } \\
\text { eksperimen. } \\
\text { penelitian } \\
\text { pengembangan, } \\
\text { dengan } \\
\text { pendekatan } \\
\text { kuantitatif yang } \\
\text { berorientasi } \\
\text { pada } \\
\text { pengembangan } \\
\text { produk.. }\end{array}$ \\
\hline $\begin{array}{l}\text { Rozek } \\
(2019)\end{array}$ & $\begin{array}{l}\text { Tindakan } \\
\text { yang } \\
\text { diberikan } \\
\text { adalah } \\
\text { membuat } \\
\text { pembalut } \\
\text { yang } \\
\text { dapat } \\
\text { digunakan } \\
\text { kembali } \\
\text { dan } \\
\text { memberik } \\
\text { an } \\
\text { pendidika } \\
\text { n } \\
\text { manajeme } \\
\text { n } \\
\text { kesehatan } \\
\text { menstrua } \\
\text { si (MKM) }\end{array}$ & $\begin{array}{l}\text { Hasil penelitian ini } \\
\text { sebagai hasil dari } \\
\text { kolaborasi } \\
\text { internasional dan } \\
\text { telah terbukti } \\
\text { berkelanjutan } \\
\text { dengan } \\
\text { penggunaan } \\
\text { pembalut dapat } \\
\text { digunakan kembali } \\
\text { produksi } \\
\text { pembalut dan } \\
\text { melanjutkan } \\
\text { pendidikan MKM } \\
\text { oleh Wanjiru di } \\
\text { seluruh } \\
\text { Kabupaten } \\
\text { Kajiado, Kenya. }\end{array}$ & $\begin{array}{lr}\text { Jenis } & \text { penelitian } \\
\text { yang } & \text { digunakan } \\
\text { adalah } & \text { studi } \\
\text { kualitatif. } & \end{array}$ \\
\hline $\begin{array}{l}\text { Efeunu, } \\
\text { E. N., \& } \\
\text { Adika } \\
(2019)\end{array}$ & $\begin{array}{l}\text { Tindakan } \\
\text { yang } \\
\text { diberikan } \\
\text { adalah } 56 \\
\text { dari } \\
\text { sekolah } \\
\text { dasar dan } \\
84 \quad \text { dari } \\
\text { sekolah } \\
\text { menengah } \\
\text { pertama } \\
\text { Kelompo } \\
\text { k umur } \\
\text { I0-20 } \\
\text { tahun } \\
\text { diberi } \\
\text { kuesioner } \\
\text { untuk } \\
\text { mengump } \\
\text { ulkan data } \\
\text { untuk } \\
\text { dianalisis. }\end{array}$ & $\begin{array}{l}\text { Hasil penelitian } \\
\text { menunjukkan } \\
\text { bahwa dari I40 } \\
\text { anak perempuan } \\
\text { yang diteliti, } 64,3 \% \\
\text { anak perempuan } \\
\text { menggunakan } \\
\text { pembalut, } 62,3 \% \\
\text { menggunakan } \\
\text { pembalut persepsi } \\
\text { diri yang positif } \\
\text { tentang } \\
\text { penggunaan } \\
\text { pembalut untuk } \\
\text { tujuan kebersihan } \\
\text { sedangkan } 67,1 \% \\
\text { merasa puas } \\
\text { sebagai serta } \\
\text { bagus dan bagus } \\
\text { karena } \\
\text { meningkatkan } \\
\text { kepercayaan diri } \\
\text { mereka. }\end{array}$ & $\begin{array}{l}\text { Metode yang } \\
\text { digunakan } \\
\text { adalah cross- } \\
\text { sectional }\end{array}$ \\
\hline
\end{tabular}

\section{PEMBAHASAN}




\section{Identifikasi Pengetahuan Siswi Tentang Pembalut kain}

Berdasarkan penelitian Efeunu, E. N., \& Adika, (2019) responden dalam penelitian ini merupakan yaitu 140 siswi sekolah di Nigeria Hasil penelitian menunjukkan bahwa dari 140 anak perempuan yang diteliti, 64,3\% anak perempuan menggunakan pembalut, $62,3 \%$ menggunakan pembalut persepsi diri yang positif tentang penggunaan pembalut untuk tujuan kebersihan sedangkan $67,1 \%$ merasa puas sebagai serta bagus dan bagus karena meningkatkan kepercayaan diri mereka. Hasil penelitian (Rozek, 2019). Lokasi penelitian Penelitian ini dilaksanakan pada pada siswi di sekolah dasar di pedesaan Kenya penelitian ini menunjukkan kepuasan secara keseluruhan terhadap produk pembalut kain serta meningkat pengetahuan dan kenyamanan siswi didesa Kenya. Hasil penelitian (Diiniyati \& Kusmaryati, 2020) penelitian ini di RT 09 Buluran Kenali Kota Jambi. Subjek pada penelitian ini berjumlah 33 orang Dari aspek penilaian pada uji coba produk memperoleh rata-rata persentase $90 \%$ pada uji coba kelompok terbatas dan pada uji coba lapangan yang termasuk dalam kategori sangat layak berdasarkan hasil tersebut maka dapat dikatakan bahwa pembalut kain yang dikembangkan memiliki kemanfaatan pada penggunanya.

Wijayanti et al., (2017), pada sebuah penelitian menyatakan bahwa kandungan pemutih atau pewangi buatan yang terdapat pada pembalut berisiko pada alergi dan memicu keputihan abnormal serta radang, iritasi dan infeksi. Akibat kurangnya informasi bagi perempuan bahwa ada sebanyak 107 bakteri per milimeter persegi ditemukan di atas pembalut. Kebersihan pembalut yang kurang baik dapat menjadi pemicu munculnya infeksi, iritasi, vaginitis (radang vagina) bahkan akumulasi dalam jangka waktu yang lama dapat memicu terjadinya kanker serviks. Penggunaan produk pembalut yang tidak berkualitas meningkatkan risiko terjadinya kanker serviks hingga 2,3 kali. Penggunaan pembalut wanita sekali pakai dalam jangka panjang berpotensi menimbulkan gangguan kesehatan pada wanita maupun lingkungan sehingga perlu disosialisasikan pembalut wanita dari kain yang dapat dipakai berulang-ulang. Pembalut wanita ramah lingkungan ini memiliki beberapa keunggulan desain dan mudah dibuat dan berpotensi untuk dipatenkan karena berbeda dengan desain pembalut wanita yang sudah ada (Habibie et al., 2019)

Berdasarkan dari ketiga penelitian terdahulu terdapat penelitian dengan hasil yang sama, yaitu antara penelitian (Efeunu, E. N., \& Adika, 2019) dengan (Rozek, 2019) dan (Diiniyati \& Kusmaryati, 2020) Hasil ketiga penelitian (Efeunu, E. N., \& Adika, 2019) dengan (Rozek, 2019) dan (Diiniyati \& Kusmaryati, 2020) yaitu kurangnya pengetahuan dalam penggunaan pembalut sekali pakai yang berisiko terhadap kesehatan reproduksi wanita. Pengetahuan yang dimaksudkan merupakan pengetahuan yang bersangkutan dengan pemilihan pembalut yang tepat, pengetahuan tentang menstruasi, pengetahuan kesehatan reproduksi pada wanita, dan pengetahuan tentang masalah-masalah reproduksi.

\section{Identifikasi Minat Siswi Tentang Pembalut kain}

Berdasarkan penelitian (Efeunu, E. N., \& Adika, 2019)responden dalam penelitian ini merupakan yaitu I40 siswi sekolah di Nigeria Hasil penelitian menunjukkan bahwa dari 140 anak perempuan yang diteliti, 64,3\% anak perempuan menggunakan pembalut, $62,3 \%$ menggunakan pembalut persepsi diri yang positif tentang penggunaan pembalut untuk tujuan kebersihan sedangkan $67,1 \%$ merasa puas sebagai serta bagus dan bagus karena meningkatkan kepercayaan diri mereka. Hasil penelitian (Rozek, 2019). Lokasi penelitian Penelitian ini dilaksanakan pada pada siswi di sekolah dasar di pedesaan Kenya penelitian ini menunjukkan kepuasan secara keseluruhan terhadap produk pembalut kain serta meningkat pengetahuan dan kenyamanan siswi didesa Kenya. Hasil penelitian 
(Diiniyati \& Kusmaryati, 2020) penelitian ini di RT 09 Buluran Kenali Kota Jambi. Subjek pada penelitian ini berjumlah 33 orang Dari aspek penilaian pada uji coba produk memperoleh rata-rata persentase $90 \%$ pada uji coba kelompok terbatas dan pada uji coba lapangan yang termasuk dalam kategori sangat layak berdasarkan hasil tersebut maka dapat dikatakan bahwa pembalut kain yang dikembangkan memiliki kemanfaatan pada penggunanya.

Pembalut wanita ramah lingkungan ini memiliki beberapa keunggulan desain dan mudah dibuat dan berpotensi untuk dipatenkan karena berbeda dengan desain pembalut wanita yang sudah ada. Berbagai macam inovasi produk alternatif telah diciptakan sebagai pengganti pembalut sekali pakai sebagai usaha mengurangi sampah pembalut sekali pakai yang setiap tahun meningkat serta mengurangi pencemaran lingkungan. Produk-produk yang dimaksud antara lain seperti cawan menstruasi (menstrual cup), pembalut kain, tampon, spons menstruasi, Selain faktor kesehatan yang menjadi masalah serius, faktor kerusakan lingkungan akibat limbah pembalut juga menjadi alasan mengapa perlu adanya transfer pengetahuan mengenai pentingnya beralih pada pembalut kain. Kelebihan yang dimliki pembalut kain antara lain sangat tahan lama bila dirawat dan dicuci dengan benar, sangat ramah lingkungan karena pembalut kain dapat digunakan berulang-ulang (Puspita, 2019). Aspek penilaian pada uji coba produk memperoleh rata-rata persentase $90 \%$ pada uji coba kelompok terbatas dan pada uji coba lapangan dikembangkan ini mempunyai kulitas sangat baik dan sangat layak, berdasarkan hasil tersebut maka dapat dikatakan bahwa pembalut kain yang dikembangkan memiliki kemanfaatan pada penggunanya.

Berdasarkan dari ketiga penelitian terdahulu terdapat kesamaan hasil penelitian berdasarkan (Efeunu, E. N., \& Adika, 2019) Hasil penelitian menunjukkan bahwa dari 140 anak perempuan yang diteliti, 64,3\% anak perempuan menggunakan pembalut, $62,3 \%$ menggunakan pembalut persepsi diri yang positif tentang penggunaan pembalut untuk tujuan kebersihan sedangkan $67,1 \%$ merasa puas sebagai serta bagus dan bagus karena meningkatkan kepercayaan diri mereka.. Rozek, (2019) penelitian ini menunjukkan kepuasan secara keseluruhan terhadap produk pembalut kain serta meningkat pengetahuan dan kenyamanan siswi didesa Kenya. Diiniyati \& Kusmaryati (2020) Aspek penilaian pada uji coba produk memperoleh rata-rata persentase $90 \%$ pada uji coba kelompok terbatas dan pada uji coba lapangan dikembangkan ini mempunyai kulitas sangat baik dan sangat layak, berdasarkan hasil tersebut maka dapat dikatakan bahwa pembalut kain yang dikembangkan memiliki kemanfaatan pada penggunanya.pembalut kain yang berhasil dikembangkan telah mendapatkan respon positif dari responden serta layak untuk digunakan dan bahan yang digunakan sesuai dengan kebutuhan dasar manusia.

\section{Analisis Hubungan Pengetahuan Dengan Minat Siswi Tentang Pembalut Kain}

Berdasarkan penelitian (Efeunu, E. N., \& Adika, 2019), Metode yang digunakan adalah cross-sectional dalam penelitian ini adalah I40 siswi sekolah di Nigeria. Hasil penelitian menunjukkan bahwa dari 140 anak perempuan yang diteliti, $64,3 \%$ anak perempuan menggunakan pembalut, 62,3\% menggunakan pembalut persepsi diri yang positif tentang penggunaan pembalut untuk tujuan kebersihan sedangkan 67,1\% merasa puas sebagai serta bagus dan bagus karena meningkatkan kepercayaan diri mereka. Penelitian (Rozek, 2019) ini dilaksanakan pada pada siswi di sekolah dasar di pedesaan Kenya penelitian ini menunjukkan kepuasan secara keseluruhan terhadap produk pembalut kain serta meningkat pengetahuan dan kenyamanan siswi didesa Kenya. Hasil penelitian (Diiniyati \& Kusmaryati, 2020) penelitian ini di RT 09 Buluran Kenali Kota Jambi. Subjek pada penelitian ini berjumlah 33 orang Dari aspek penilaian pada uji coba produk memperoleh rata-rata persentase $90 \%$ pada uji coba kelompok terbatas dan pada uji coba lapangan yang 
termasuk dalam kategori sangat layak berdasarkan hasil tersebut maka dapat dikatakan bahwa pembalut kain yang dikembangkan memiliki kemanfaatan pada penggunanya.

Pembalut wanita ramah lingkungan ini memiliki beberapa keunggulan desain dan mudah dibuat dan berpotensi untuk dipatenkan karena berbeda dengan desain pembalut wanita yang sudah ada (Habibie et al., 2019). Remaja putri memiliki sikap dan pengetahuan yang masih rendah terkait manajemen dalam menghadapi menstruasi yang pada akhirnya berimbas pada penggunaan pembalut yang kurang tepat (Manuaba, 20I5). Penggunaan pembalut yang kurang tepat dapat berimplikasi pada terjadinya berbagai masalah kesehatan reproduksi. Perilaku penggunaan pembalut diinisiasi oleh domain pengetahuan dan sikap. Menggalakkan upaya untuk mendapatkan dan dapat memanfaatkan produk bahan dan corak pakaian setempat dengan mencintai produk dalam negeri wanita (Ardiyati \& Pramitasari, 2019). Kelebihan yang dimliki pembalut kain antara lain sangat tahan lama bila dirawat dan dicuci dengan benar, sangat ramah lingkungan karena pembalut kain dapat digunakan berulang-ulang. Pembalut kain ini di uji coba terbatas dan di uji coba dilapangan pada perempuan di RT 09 Buluran Kenali Kota Jambi. Subjek pada penelitian ini berjumlah 33 orang dilakukan pada bulan Januari sampai November 2019.Uji coba di daptkan hasil ratarata dalam menjawab instrument mencapai $90 \%$ sehingga menghasilkan pembalut kain yang ramah lingkunganKeunggulan Desain, meliputi harga bahan baku yang murah dan produk mudah dibuat, serta bahan yang digunakan mudah dijumpai (Habibie et al., 2019)

Berdasarkan hasil penelitian dari ketiga penelitian terdahulu terdapat kesamaan hasil penelitian, yaitu terdapat hubungan pengetahuan dengan minat. Menurut peneliti hal ini terjadi dikarenakan ketiga penelitian ini memiliki karakteristik subjek yang sama, yaitu responden penelitian merupakan perempuan yang sudah mengalami menstruasi dan kesamaan penelitian dalam pemilihan pembalut yang tepat dan aman untuk kesehatan reproduksi perempuan. Seorang wanita diharapkan dapat memilih pembalut yang tepat. Kesalahan memilih pembalut bisa berakibat iritasi kulit, alergi, hingga penyakit kulit dan infeksi. Pemilihan pembalut juga disesuaikan degan aktivitas yang akan dilakukan seorang wanita.

\section{KESIMPULAN}

Berdasarkan hasil telah dari ketiga jurnal dimana hasil data sekunder penelitian ini dapat menjadi bahan pertimbangan dalam pemilihan pembalut bahwa ada hubungan tingkat pengetahuan, minat dan kualitas pembalut terhadap risiko kanker serviks pada siswi. Diantara faktor tersebut yakni pengetahuan dan kesadaran individu. Hal tersebut sesuai dengan hasil analisis dalam penelitian ini. Pengetahuan yang dimaksudkan merupakan pengetahuan yang bersangkutan dengan pemilihan pembaulut, personal hygiene diantaranya pengetahuan tentang menstruasi, pengetahuan kesehatan reproduksi pada wanita dan pengetahuan mengenai kebersihan diri pada wanita baik saat menstruasi maupun dalam keseharian. Dengan demikian, dalam tatanan praktis intervensi perilaku higienitas dan kesehatan organ reproduksi pada remaja putri sebaiknya tidak hanya dititik beratkan pada perubahan aspek pengetahuan dan sikap, tetapi dengan mempertimbangkan variabel kontributor yang lain. Selain itu, intensitas paparan informasi tentang higienitas dan kesehatan organ reproduksi pada siswi Sekolah Menengah Pertama/ Sederajat perlu ditingkatkan lagi utamanya dalam pemilihan dan penilaian produk pembalut yang aman; durasi penggantian pembalut; dan dampak penggunaan pembalut yang kurang tepat.

Berdasarkan hasil telaah dari ketiga jurnal dimana hasil data sekunder dimana hasil terdapat kesesuaian yang menunjukan bahwa terdapat Hubungan Pengetahuan Siswi Dengan Minat Dalam Pemilihan Pembalut Kain 
yang menunjukkan bahwa tingkat pengetahuan seseorang berhubungan dengan minat dalam mengambil keputusan dalam pemilihan pembalut yang yang aman untuk kesehatan reproduksi.

Memiliki informasi dan pengalaman yang banyak, semakin banyak informasi yang didapat maka pengetahuan seseorang akan bertambah baik dengan semakin banyaknya infomasi yang didapat maka pola pikirnya seseorang akan semakin terbuka dan dapat mencari solusi dari suatu masalah sehingga informasi didapat oleh seseorang didukung juga media yang digunakan yang juga dapat mempengaruhi sikap seseorang dalam bersikap, semakin banyak pengalaman seseorang maka pengetahuannya akan menjadi baik dimana pengalaman yang banyak akan menjadi suatu perbandingan dan pembelajaran bagi seseorang untuk menentukan sikap yang lebih baik.

\section{UCAPAN TERIMA KASIH}

Penulis sadar banyak hambatan dalam proses penyusunan penelitian ini, dikarenakan keterbatasan kemampuan penulis sendiri. Oleh Karena itu penulis sampaikan banyak terimakasih kepada semua pihak yang telah memberikan bantuannya, utamanya kepada yang terhormat:

\section{Ketua Yayasan Eka Harap}

2. Ketua STIKes Eka Harap

3. Kaprodi Sarjana IImu Keperawatan STIKES Eka Harap

4. Kaprodi Profesi Ners STIKES Eka Harap

\section{REFERENSI}

I. Wati, P. S., Ririanty, M., \& Nafikadini, I. (2019). Perilaku Menjaga Kebersihan Organ Genetalia Pada Konsumen Pembalut Herbal. Jurnal Kesehatan. https://doi.org//0.25047/j-kes.v7il.7I

2. Habibie, M., Rohmah, N., Rahmadhini, V. A., Indryani, M., Kholifah, W., Danu Prasetiya, A., Zam-Zami, R. A., Ayuningtyas, I. R., \& Fathudin, A. (2019). Pemberdayaan Wanita Melalui Pelatihan
Pembuatan Pembalut Ramah Lingkungan di Dusun Jambu. Prosiding Konferensi Pengabdian Masyarakat.

3. Susanti, E. M., \& Wijaya, P. S. (20/8). Perbedaan Penggunaan Pembalut Dan Pantyliner Jenis Biasa, Herbal, Dan Kain Dengan Kejadian Keputihan. Indonesia Jurnal Kebidanan. https://doi.org//0.2675I/ijb.v2il.427

4. Kementrian Kesehatan RI. (2018). Profil Kesehatan Indonesia 2018 Kemenkes RI. http://www.depkes.go.id/resources/download/pus datin/profil-kesehatan-indonesia/Data-danInformasi_Profil-Kesehatan-Indonesia-2018.pdf

5. Susanti, E. M., \& Wijaya, P. S. (20/8). Perbedaan Penggunaan Pembalut Dan Pantyliner Jenis Biasa, Herbal, Dan Kain Dengan Kejadian Keputihan. Indonesia Jurnal Kebidanan. https://doi.org//0.2675I/ijb.v2il.427

6. Ardiyati, A., \& Pramitasari, R. (2019). Ecoliteracy Penggunan Pembalut Wanita Ramah Lingkungan Kelompok PKK Dusun Panggang, Argomulyo, Sedayu. Prosiding Seminar Hasil Pengabdian Masyarakat.

7. Diiniyati, D., \& Kusmaryati, P. (2020). Pengembangan Pembalut Kain Yang Ramah Lingkungan Sebagai Alternatif Pilihan Untuk Kesehatan Reproduksi Perempuan. Jurnal Media Kesehatan. https://doi.org/I0.33088/jmk.vI3il.488

8. Rozek, M. (2019). Reducing School Absenteeism through Reusable Sanitary Pad Project in Namanga, Kenya.

9. Efeunu, E. N., \& Adika, V. O. (2019). Risk Factors Associated With Unwanted Pregnancy and Reproductive Health Education Needs of Adolescent School Girls in Amassoma Community, Bayelsa State.

10. Diiniyati, D., \& Kusmaryati, P. (2020). Pengembangan Pembalut Kain Yang Ramah Lingkungan Sebagai Alternatif Pilihan Untuk Kesehatan Reproduksi Perempuan. Jurnal Media Kesehatan. https://doi.org/I0.33088/jmk.v/3il.488

II. Wijayanti, A., Sumiyarsi, I., \& Nugraheni, A. (2017). Hubungan Antara Penggunaan Jenis Pembalut Saat Menstruasi Dengan Kejadian Keputihan Di SMK Negeri I Sukoharjo. Jurnal 
EDUMidwifery.

12. Manuaba. (20I5). Ilmu Kebidanan. EGC: Jakarta.

13. Dinas Kesehatan Kota Palangka Raya. (2018). Profil Kesehatan Kota Palangka Raya. 